\title{
SURVEY INSTRUMENT DEVELOPMENT FOR CONSUMER PERCEPTION TESTING TO RTE PRODUCT IN CONVENIENCE STORE
}

\author{
Dyah Lestari Widaningrum'; Wiwit Amrinola ${ }^{2}$; Fuadi Nasution ${ }^{3}$ \\ ${ }^{1,2,3}$ Industrial Engineering Department, Faculty of Engineering, BINUS University \\ Jl. KH. Syahdan no. 9, Palmerah, Jakarta Barat, Indonesia \\ ${ }^{1}$ dwidaningrum@binus.edu; ${ }^{2}$ wamrinola@binus.edu
}

\begin{abstract}
Global trade and the abolition of trade barriers lead to the proliferation of imported food products such as various types of fast food products (RTE: ready-to-eat food) sold by convenience stores mainly scattered in Jakarta. The question is what causes consumers choose certain convenience store to buy RTE Product and not choose another outlet category. To understand consumer perceptions, it is necessary to develop an instrument for measuring consumer perceptions of the option to purchase RTE Product at convenience stores. Variables used in this research are the perception and knowledge of the public/consumers against food safety, store Attributes, service, and Product attributes. The instrument used in this study is a questionnaire with a scale measuring1-5 to see the relationship between variables, we used the method of Structural Equation Modeling (SEM). The sample used in this study was 223 respondents that were divided into five areas in Jakarta, namely Central Jakarta, West Jakarta, South Jakarta, East Jakarta, and North Jakarta. The final outcome of the instrument development process was 25 observed variables, consisting of 4 indicators, which valid and reliable, with T-values for each observed variable is above 2,58, and Construct Reliability values range between 0,76 to 0,853 .
\end{abstract}

Keywords: RTE/Ready-To-Eat food, convenience store, food safety, store attribute, product attribute, Structural Equation Modeling (SEM)

\begin{abstract}
ABSTRAK
Perdagangan global dan dihapuskannya hambatan perdagangan mengakibatkan bertambah banyak produk pangan impor seperti berbagai jenis produk pangan siap konsumsi (RTE: ready-to-eat product) yang dijual oleh convenience store terutama yang tersebar di wilayah Jakarta. Yang menjadi pertanyaan adalah apa yang menyebabkan konsumen memilih convenience store tertentu untuk membeli RTE Product dan tidak memilih outlet yang lain. Untuk memahami persepsi konsumen ini maka perlu dikembangkan suatu instrumen untuk mengukur persepsi konsumen terhadap penentuan pilihan untuk membeli RTE Product di convenience store. Variabel yang digunakan dalam penelitian ini adalah persepsi dan pengetahuan masyarakat/konsumen terhadap food safety, atribut dari convenience store (secara fisik), atribut layanan, dan atribut dari produk yang dijual. Untuk mengetahui persepsi dari konsumen, maka disusun instrumen berupa kuesioner dengan skala pengukuran 1-5. Untuk melihat keterkaitan antar variabel, maka digunakan metode Structural Equation Modeling (SEM). Sampel yang digunakan dalam penelitian ini sebanyak 223 responden yang terbagi dalam lima wilayah yang ada di Jakarta, yaitu Jakarta Pusat, Jakarta Barat, Jakarta Selatan, Jakarta Timur, dan Jakarta Utara. Hasil akhir dari proses pengembangan instrumen ini adalah dihasilkannya 25 variabel observasi, yang terbagi ke dalam 4 indikator, yang valid dan reliabel, dengan nilai T-values di atas 2,58, dan kisaran nilai Construct Reliability antara 0,76 sampai 0,853.
\end{abstract}

Kata kunci: RTE/Ready-To-Eat food, convenience store, food safety, store attribute, product attribute, Structural Equation Modeling (SEM) 


\section{PENDAHULUAN}

Perkembangan suatu wilayah terkadang disertai dengan pertumbuhan berbagai macam tipe retail. Semakin tinggi tingkat perekonomian suatu daerah, maka jarak antara retail yang satu dengan yang lainnya pun menjadi semakin dekat, mengikuti aturan supply dan demand. Ada berbagai macam format retail, namun yang akan dibahas spesifik pada format retail yang dikenal dengan convenience store, yaitu format retail tersebut saat ini sedang berkembang di Indonesia, terutama di kota-kota besar seperti Jakarta, Bandung, Bali, dan lain-lain. Convenience store yang dibahas dalam penelitian ini adalah jenis convenience store yang menggabungkan konsep retail dengan konsep restoran cepat saji, dimana pembeli tidak hanya dapat membeli produk-produk consumer goods, tapi juga dapat membeli beragam produk siap konsumsi (ready-to-eat product atau RTE product), dan bahkan dapat menikmati produk yang mereka beli di area yang telah disediakan.

Perkembangan retail stores di Jepang dimulai pada tahun 1970-an dan juga diramaikan dengan format convenience store di tahun 1974. Ito Yokado membuka toko pertamanya dengan brand Seven-Eleven, yang diikuti oleh Lawson, FamiliMart, MiniStop, Circle K, dan Sankus (Meyer-Ohle, 2003). Untuk meningkatkan pelayanan kepada pelanggan, convenience store menyediakan berbagai macam fasilitas seperti layaknya sebuah restoran, sebuah lobby atau ruang makan yang nyaman, Wi-Fi dan akses listrik yang biasanya dibutuhkan untuk mengisi daya laptop atau handphone. Dengan fasilitas ini, berbagai kebutuhan pelanggan dapat terpenuhi saat berbelanja di convenience store karena pelangganm dating tidak hanya untuk makan/minum, tapi juga untuk bertemu teman, rekan bisnis atau mencari suasana baru. Apakah berbagai macam pemenuhan kebutuhan ini menjadi faktor pendorong bagi konsumen untuk membeli RTE product di convenience store?

Pembeli dapat mengkonsumsi berbagai jenis dari makanan dan minuman yang disediakan. Berbagai makanan dan minuman dapat dikonsumsi langsung karena kesegaran dari makanan atau minuman tersebut dijaga dengan metode pengemasan tertentu (vacuum pack, aseptic pack, dan lainlain) atau melalui sistem display tertentu (hot snack display, food/soup warmer, cooler, soft drink dispenser, dan lain-lain) seperti roti, donat, fried chicken, burger, hotdog, dan termasuk berbagai jenis minuman. Pembeli juga dapat membeli berbagai jenis makanan dan minuman yang disajikan dengan cepat (quick service food and drink) dengan dibantu oleh operator store untuk memanaskan makanan menggunakan microwave atau mengoperasikan mesin kopi. Pembeli juga mengambil sendiri kopi, teh, minuman es, dan lain sebagainya. Apakah produk makanan/minuman yang ditawarkan serta pelayanan yang diterima oleh konsumen menjadi faktor pendorong bagi konsumen untuk membeli RTE product di convenience store?

Pengalaman dan nilai kepraktisan ketika pelanggan membeli RTE product menjadi salah satu faktor yang menarik pelanggan untuk berbelanja di convenience store. Berman \& Evans (2006) menjelaskan bahwa retailer harus bisa mengidentifikasi dan memahami pelanggan dalam hal demografi, gaya hidup, kebutuhan, ekspektasi, serta persepsi mereka terhadap lingkungan dan aktifitas retail. Sebagai unit usaha yang berbadan hukum, convenience store memperhatikan kaidah food safety dalam menangani RTE product yang dijual karena baik secara langsung maupun tidak langsung akan dimonitor oleh lembaga-lembaga pemerintahan. Perlu dipelajari lebih lanjut, apakah konsumen memandang kaidah-kaidah food safety dalam menangani produk adalah suatu hal yang penting sehingga menjadi salah satu faktor yang berpengaruh dalam mengkonsumsi RTE product dari convenience store?

Berdasarkan hasil penelitian yang dilakukan oleh Conte et al (2012) tentang functional RTE, indikator dari atribut produk pangan yang dijual itu sendiri (Product attributes) diantaranya adalah kandungan gizi dari makanan tersebut, variasi jenis makanan yang disediakan, ketersediaan label makanan, dan porsi makanan itu sendiri. Sedangkan indikator atribut untuk Take-away RTE menurut 
Binkley et. al., (2008) adalah kemasan, dan informasi kadaluarsa (expired) dari makanan tersebut boleh untuk dikonsumsi. Atribut lain yang menjadi perhatian konsumen dalam penentuan kunjungan ke convenient stores adalah store attributes itu sendiri. Indikator atributnya antara lain adalah lokasi, keamanan, promosi, dekorasi ruangan, kebersihan, area bermain anak, fasilitas parkir, convenient hours, dan pelayanan (Jhamb, 2012).

Penelitian ini bertujuan untuk mengetahui faktor apa saja yang akan mempengaruhi perilaku konsumen dalam membeli dan mengkonsumsi RTE product dari convenience store. Penelitian ini dimulai dengan menentukan faktor-faktor yang mempengaruhi pembelian RTE product dari convenience store dilanjutkan dengan desain instrumen dengan menentukan item scale dari masingmasing variable berdasarkan studi pustaka. Pembahasan akan mencakup pengujian validitas dan reliabilitas dari instrumen yang dihasilkan sehingga diperoleh instrumen untuk menguji persepsi konsumen terhadap RTE product di convenience store. Instrumen yang dihasilkan ini akan menjadi dasar untuk pelaksanaan penelitian lanjutan yang diantaranya adalah untuk melihat korelasi persepsi terhadap variabel-variabel pada instrumen ini dengan variabel lain, misalnya willingness to buy. Penelitian lanjutan dilakukan untuk lebih memahami persepsi serta perilaku dari konsumen, agar dapat menentukan desain produk yang sesuai dengan harapan dari konsumen, sebagai langkah untuk mencapai tingkat kepuasan pelanggan.

\section{METODE}

Penelitian diawali dengan tinjauan pustaka, untuk menentukan faktor apa saja yang mempengaruhi persepsi konsumen terhadap RTE product, serta item test dari setiap faktor atau variabel laten. Pemilihan dan penentuan item test, pilot test dan confirmatory study merupakan bagian dari tahapan pengembangan instrument survey seperti yang telah dipaparkan dan dibuktikan oleh Dwivedi et. al., (2006). Pemilihan dan penentuan item test dilakukan berdasarkan studi yang pernah dilakukan sebelumnya seperti yang telah dibahas oleh Widaningrum dan Amrinola (2014). Setelah penentuan dan pemilihan item test, selanjutnya dilaksanakan pilot test terhadap 100 responden, untuk uji awal apakah instrumen yang didesain dapat dipahami dengan baik oleh responden. Untuk uji statistik, untuk mengetahui signifikansi dari instrument yang didesain, maka digunakan metode Confirmatory Factor Analysis, dengan menggunakan software LISREL 8.72.

\section{HASIL DAN PEMBAHASAN}

Pada penelitian ini, pilot test dilaksanakan pada 100 responden, untuk melakukan pre-testing terhadap instrumen penelitian yang dikembangkan. Hasil dari pengujian reliabilitas dengan mengukur nilai Cronbach's Alpha bervariasi 0,71 untuk construct Service, 0,76 untuk construct Safety, dan 0,85 untuk construct Product dan Store. Keseluruhan construct memiliki nilai Cronbach's Alpha lebih besar dari 0,70 mengindikasikan bahwa keempat construct memiliki konsistensi internal yang baik, sehingga penggunaan instrumen ini untuk penelitian bisa dilanjutkan.

Analisis deskriptif merupakan salah satu bentuk analisis statistik yang digunakan untuk menunjukkan nilai pusat dan variasi dari seluruh variabel. Responden sebanyak 223 diambil secara acak pada beberapa convenience store yang berada pada 5 wilayah di Jakarta, yaitu Jakarta Barat, Jakarta Timur, Jakarta Selatan, Jakarta Utara, dan Jakarta Pusat. Penyebaran wilayah sampling ini bertujuan untuk mengurangi bias respon yang dapat ditimbulkan karena perbedaan geografis dan untuk merepresentasikan konsumen dari convenience store yang ada di kota Jakarta. 
Nilai rataan (mean) untuk variabel laten product adalah 3,35; Service 3,64; Store 3,69; dan Safety 3,97. Standar deviasi untuk masing-masing variable laten tersebut berkisar antara 0,83-0,95, dengan nilai standar deviasi berkisar antara 0.83-0.95. Dari hasil pengukuran statistik tersebut dapat dikatakan bahwa responden secara umum setuju dengan pernyataan pada kuesioner. Nilai skewness dan kurtosis berfungsi untuk melihat penyebaran normal data yang digunakan dalam penelitian ini. Dari nilai skewness dan kurtosis yang diperoleh dapat dilihat bahwa distribusi data normal dengan nilai lebih rendah dari \pm 3 untuk skewness dan jauh lebih rendah dari \pm 10 untuk kurtosis.

Untuk menguji apakah alat pengukuran valid dan reliabel, maka dilakukan Confirmatory Factor Analysis, menggunakan LISREL 8.2. Nilai Construct Reliability di atas 0,70 menunjukkan internal consistency yang baik dari instrument (Wijanto, 2008).

\section{Atribut: Product}

Nilai Construct Reliability dari varibel laten product adalah 0,85. Hal ini membuktikan bahwa variabel laten Product memiliki reliabilitas yang baik dengan nilai lebih dari 0,70 dan mengindikasikan adanya konsistensi internal. $T$-values dari seluruh variabel observasi lebih tinggi dari 2,58 dan standardize loading factor dari seluruh variabel observasi paling kecil nilainya adalah 0,49 menunjukkan bahwa keseluruhan variabel observasi adalah valid sebagai indikator untuk melakukan pengukuran variabel laten (Tabel 1) dan CFA model dapat dilihat pada Gambar 2.

Tabel 1 Validitas dan Reliabilitas Model Pengukuran Product (n=223)

\begin{tabular}{clcccc}
\hline Variabel Laten & Variabel Observasi & t-value & Standardized Coefficient & $\mathbf{R}^{2}$ & Construct Reliability \\
\hline Product (PR) & & & & 0,85 \\
\hline & Rasa (PR1) & 9,00 & 0,59 & 0,35 & 0,40 \\
& Ragam (PR2) & 9,82 & 0,64 & 0,34 \\
& Tampilan (PR3) & 8,83 & 0,58 & 0,49 \\
& Keamanan (PR4) & 11,16 & 0,70 & 0,50 \\
& Cara Kemas (PR5) & 11,31 & 0,71 & 0,57 \\
& Jenis Kemasan (PR6) & 12,34 & 0,75 & 0,38 \\
& Harga (PR7) & 9,54 & 0,62 & 0,30 \\
& Ketersediaan (PR8) & 8,23 & 0,55 & 0,24 \\
\hline
\end{tabular}
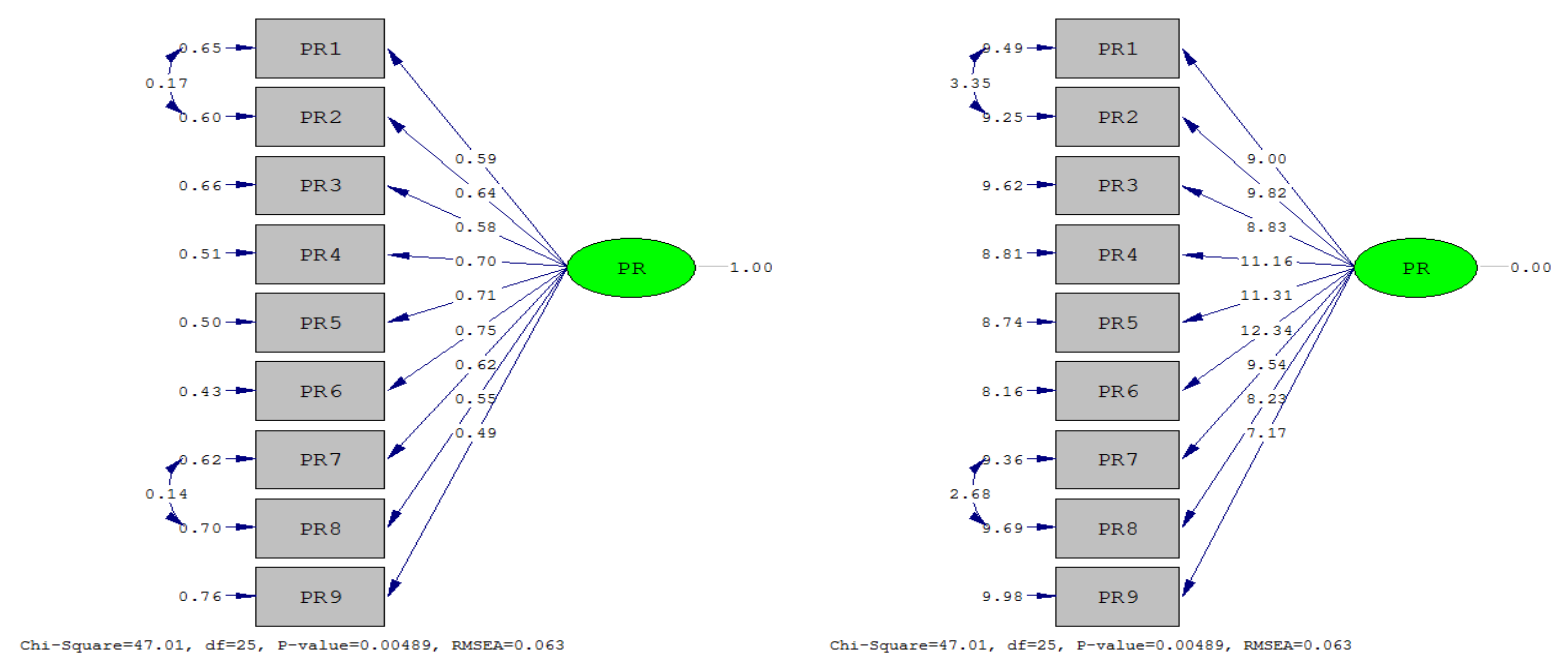

Gambar 1 CFA Model untuk Product 
Tabel 2 menunjukkan nilai index fit dari Confirmatory Factor Analysis model untuk variabel laten product pada level yang dapat diterima atau model pengukuran dinyatakan GOOD FIT.

Tabel 2 Confirmatory Factor Analysis Fit Indexes (n=223)

\begin{tabular}{cccccc}
\hline \multirow{2}{*}{ Good Fit Indexes } & $\chi^{2} / \mathbf{d f}$ & RMSEA & NFI & NNFI & CFI \\
\cline { 2 - 6 } & $\mathbf{1 , 0 0} \sim \mathbf{3 , 0 0}$ & $\mathbf{0 , 0 5} \sim \mathbf{0 , 0 8}$ & $>\mathbf{0 , 9 0}$ & $>\mathbf{0 , 9 0}$ & $>\mathbf{0 , 9 0}$ \\
\hline Product & 2,09 & 0,06 & 0,96 & 0,97 & 0,98 \\
\hline
\end{tabular}

\section{Atribut: Service}

Nilai Construct Reliability dari varibel laten service adalah 0,76. hail ini membuktikan bahwa variabel laten service memiliki reliabilitas yang baik. $T$-values dari seluruh variabel observasi lebih tinggi dari 2,58 dan standardize loading factor dari seluruh variabel observasi lebih tinggi dari 0,50 menunjukkan bahwa keseluruhan variabel observasi adalah valid sebagai indikator untuk melakukan pengukuran variabel laten (Tabel 3).

Tabel 3 Validitas dan Reliabilitas Model Pengukuran service $(\mathrm{n}=223)$

\begin{tabular}{clcccc}
\hline Variabel Laten & \multicolumn{1}{c}{ Variabel Observasi } & t-value & Standardized Coefficient & $\mathbf{R}^{2}$ & Construct Reliability \\
\hline Service (SE) & & & & & 0,71 \\
\hline & Pengetahuan Pegawai (SE1) & 8,62 & 0,63 & 0,39 & \\
& Keramahan Pegawai (SE2) & 9,51 & 0,69 & 0,48 & \\
& Pegawai Sigap (SE3) & 9,48 & 0,69 & 0,48 & \\
& Jam Layanan (SE4) & 5,61 & 0,42 & 0,18 & \\
\hline
\end{tabular}

CFA model untuk Service dapat dilihat pada Gambar 2 berikut.

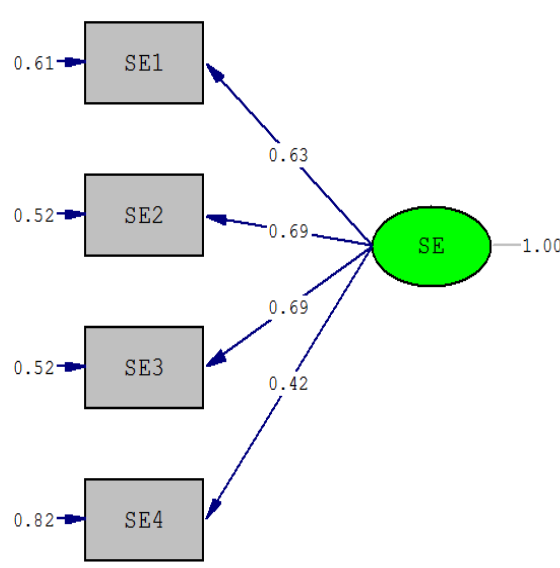

Chi-Square $=5.34, \mathrm{df}=2, \mathrm{P}-\mathrm{value}=0.06924, \mathrm{RMSEA}=0.087$

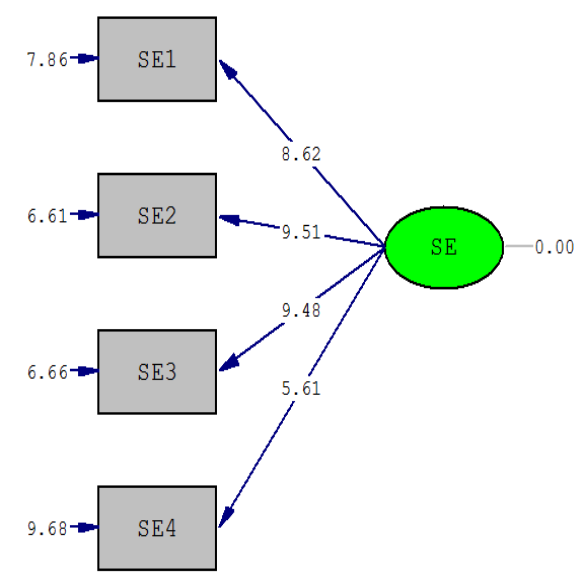

Chi-Square $=5.34, \mathrm{df}=2, \mathrm{P}-\mathrm{value}=0.06924, \mathrm{RMSEA}=0.087$

Gambar 2 CFA Model untuk service 
Tabel 4 menunjukkan nilai index fit dari Confirmatory Factor Analysis model untuk variabel laten service berada pada level yang dapat diterima atau model pengukuran dinyatakan GOOD FIT.

Tabel 4 Confirmatory Factor Analysis Fit Indexes $(\mathrm{n}=223)$

\begin{tabular}{cccccc}
\hline \multirow{2}{*}{ Good Fit Indexes } & $\chi^{2} / \mathbf{d f}$ & RMSEA & NFI & NNFI & CFI \\
\cline { 2 - 6 } & $\mathbf{1 , 0 0 ~} \mathbf{3 , 0 0}$ & $\mathbf{0 , 0 5 ~} \mathbf{0 , 0 8}$ & $>\mathbf{0 , 9 0}$ & $>\mathbf{0 , 9 0}$ & $>\mathbf{0 , 9 0}$ \\
\hline Service (SE) & 2,58 & 0,09 & 0,97 & 0,95 & 0,98 \\
\hline
\end{tabular}

\section{Atribut: Store}

Nilai Construct Reliability dari varibel laten Store Attribute adalah 0,825. Hal ini membuktikan bahwa ketiga variabel laten memiliki reliabilitas yang baik, dengan nilai lebih dari 0,70. T-values dari seluruh variabel observasi lebih tinggi dari 2,58 dan standardized loading factor dari seluruh variabel observasi lebih tinggi dari 0,50 menunjukkan bahwa keseluruhan variabel observasi adalah valid sebagai indikator untuk melakukan pengukuran variabel laten. Output dari Pengujian Store Attribute dapat dilihat pada Tabel 5.

Tabel 5 Validitas dan Reliabilitas Model Pengukuran Store attribute $(\mathrm{n}=223)$

\begin{tabular}{clcccc}
\hline Variabel Laten & \multicolumn{1}{c}{ Variabel Observasi } & t-value & $\begin{array}{c}\text { Standardized } \\
\text { Coefficient }\end{array}$ & $\mathbf{R}^{2}$ & $\begin{array}{c}\text { Construct } \\
\text { Reliability }\end{array}$ \\
\hline Store (ST) & & & & 0,83 \\
\hline & Lokasi Store (ST1) & 7,49 & 0,54 & 0,29 \\
& Layout Store (ST2) & 8,84 & 0,62 & 0,38 \\
& Desain Store (ST3) & 10,97 & 0,69 & 0,48 \\
& Kebersihan Area Store (ST4) & 12,17 & 0,78 & 0,61 \\
& Area Parkir (ST5) & 12,29 & 0,76 & 0,57 \\
& Informasi tentang Promosi (ST6) & 8,80 & 0,58 & 0,33 \\
\hline
\end{tabular}

Gambar 3 berikut menunjukkan CFA model untuk variabel Store attribute


Chi-Square-13.70, df-6, P-value-0.03321, RMSEA-0.076

Gambar 3 CFA Model untuk Store attribute 
Tabel 6 menunjukkan nilai index fit dari Confirmatory Factor Analysis model untuk variabel laten Store attribute berada pada level yang dapat diterima atau model pengukuran dinyatakan GOOD FIT.

Tabel 6 Confirmatory Factor Analysis Fit Indexes (n=223)

\begin{tabular}{cccccc}
\hline \multirow{2}{*}{ Good Fit Indexes } & $\chi^{2} / \mathbf{d f}$ & RMSEA & NFI & NNFI & CFI \\
\cline { 2 - 6 } & $\mathbf{1 , 0 0} \sim \mathbf{3 , 0 0}$ & $\mathbf{0 , 0 5 ~} \mathbf{0 , 0 8}$ & $>\mathbf{0 , 9 0}$ & $>\mathbf{0 , 9 0}$ & $>\mathbf{0 , 9 0}$ \\
\hline Store (ST) & 2,47 & 0,08 & 0,98 & 0,96 & 0,99 \\
\hline
\end{tabular}

\section{Atribut: Food Safety}

Variabel laten Food safety terdiri dari 7 variabel observasi. Output dari Pengujian CFA dapat dilihat pada Tabel 7 dan Gambar 4.

Tabel 7 Validitas dan Reliabilitas Model Pengukuran Food safety $(\mathrm{n}=223)$

\begin{tabular}{clcccc}
\hline $\begin{array}{c}\text { Variabel } \\
\text { Laten }\end{array}$ & \multicolumn{1}{c}{ Variabel Observasi } & t-value & $\begin{array}{c}\text { Standardized } \\
\text { Coefficient }\end{array}$ & $\mathbf{R}^{2}$ & $\begin{array}{c}\text { Construct } \\
\text { Reliability }\end{array}$ \\
\hline Safety (SF) & & & & & 0.825 \\
\hline & RTE Product tanpa kemasan (SF1) & 5,96 & 0,41 & 0,17 & \\
& Pentingnya mencuci tangan (SF2) & 12,18 & 0,74 & 0,54 & \\
& Pentingnya melindungi luka (SF3) & 14,42 & 0,83 & 0,68 & \\
& Pentingnya menggunakan sarung tangan (SF4) & 13,00 & 0,77 & 0,59 & \\
& Rentang waktu display RTE Product (SF5) & 0,44 & 0,03 & 0,001 & \\
& Pentingnya Clean as you go (SF6) & 13,01 & 0,77 & 0,59 & \\
& Pentingnya menjaga suhu RTE Product (SF7) & 12,16 & 0,73 & 0,54 & \\
\hline
\end{tabular}

Nilai reliabilitas konstruk (Construct Reliability) dari varibel laten Food safety adalah 0.825 . Hal ini membuktikan bahwa variabel laten tersebut memiliki reliabilitas yang baik dengan nilai lebih dari 0.70. T-values dari seluruh variabel observasi lebih tinggi dari 2.58, kecuali pada variable observasi ke-5 (SF5) dengan nilai 0,44. Sedangkan standardize loading factor dari seluruh variabel observasi lebih tinggi dari 0.50 kecuali pada variabel observasi ke-5 (SF5) dengan nilai 0,03 menunjukkan 6 variabel observasi adalah valid sebagai indikator untuk melakukan pengukuran variabel laten, sementara variabel 5 untuk analisa selanjutnya dapat dikeluarkan. 

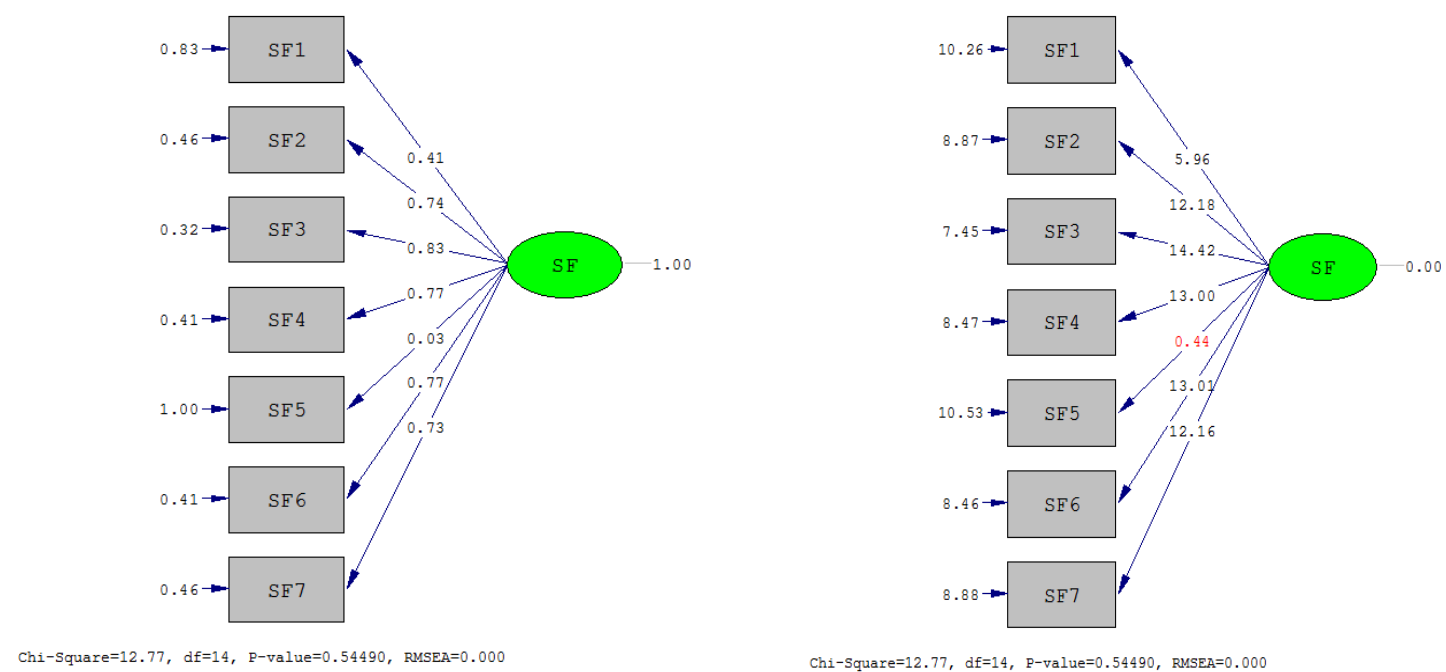

Gambar 4 CFA Model untuk Food Safety

Tabel 8 menunjukkan nilai index fit dari Confirmatory Factor Analysis model untuk variabel laten Food safety, dengan kesimpulan index fit pada level yang dapat diterima atau model pengukuran dinyatakan GOOD FIT.

Tabel 8 Confirmatory Factor Analysis Fit Indexes (n=223)

\begin{tabular}{cccccc}
\hline \multirow{2}{*}{ Good Fit Indexes } & $\chi^{2} / \mathbf{d f}$ & RMSEA & NFI & NNFI & CFI \\
\cline { 2 - 6 } & $\mathbf{1 , 0 0 ~} \mathbf{3 , 0 0}$ & $\mathbf{0 , 0 5} \sim \mathbf{0 , 0 8}$ & $>\mathbf{0 , 9 0}$ & $>\mathbf{0 , 9 0}$ & $>\mathbf{0 , 9 0}$ \\
\hline Safety & 0,91 & 0,00 & 0,99 & 1,00 & 1,00 \\
\hline
\end{tabular}

\section{SIMPULAN}

Hasil pengujian keseluruhan construct pada pilot test menghasilkan nilai yang lebih besar dari 0,70, hal ini mengindikasikan bahwa construct yang dirancang memiliki konsistensi internal yang baik sehingga instrumen yang sudah dirancang dapat digunakan dalam penelitian ini. Pada pengujian reliabilitas model pengukuran dengan menggunakan LISREL 8.2 untuk masing-masing variabel (Food Safety, Product, Store, dan Service), diperoleh hasil bahwa kisaran nilai Construct Reliability berkisar antara 0,76 sampai 0,853 , menunjukkan bahwa keempat variabel memiliki reliabilitas yang baik.

Nilai $T$-values berkisar antara 0,44 sampai 14,42. Berarti secara keseluruhan nilai $T$-values ini berada di atas 2,58, kecuali pada SF5 (rentang waktu display RTE product) yang bernilai 0,44. Hal ini menandakan bahwa secara keseluruhan indikator yang digunakan pada penelitian ini adalah valid. Sementara nilai standardized loading factor secara keseluruhan berada di atas 0.5, kecuali pada product dengan nilai 0,49 , SF1 dengan nilai 0,41, dan SF5 dengan nilai 0,03. Variabel observasi ke-5 dari variabel safety dapat dipertimbangkan untuk dikeluarkan dari model/instrumen untuk meningkatkan reliabilitas dan validitas dari instrumen.

Indeks dari pengujian Confirmatory Factor Analysis menunjukkan bahwa keempat variabel memiliki model yang fit terhadap data yang dikumpulkan, sehingga dapat disimpulkan bahwa instrumen yang didesain dapat digunakan untuk penelitian selanjutnya. 


\section{DAFTAR PUSTAKA}

Berman, B., Evans, J. R. (2006). Retail Management: A Strategic Approach (Tenth ed.). Pearson Prentice Hall.

Binkley, M., Broz, C. C., Boyce, J., Kim, H. (2008). Consumer Perception of Take-Out Food: Safe Handling Practices and Desired Package Attributes. FSMEC, 3(1).

Conte, A., Stasi, A., Pilone, V., Gammariello, D., Padalino, L. (2012). Technological and Economic Optimization of Functional Ready to Eat Meal. Journal of Food Research, 1(3)

Dwivedi, Y.K., Jyoti, C., Brinkman, W.P. (2006). Development of a survey instrument to examine consumer adoption of broadband. Industrial Management \& Data Systems, 106(5): 700-718

Jhamb, D., Kiran, R. (2012). Emerging Retail Formats and It's Attributes: An Insight to Convenient Shopping. Global Journal of Management and Business Research, 12(2).

Meyer-Ohle, H. (2003). Innovation and Dynamics in Japanese Retailing From Techniques to Format to Systems. Palgrave Macmillan.

Widaningrum, D. L., Amrinola, W. (2014). Persepsi konsumen terhadap food safety dan ekspektasi terhadap product \& store attributes serta pengaruhnya terhadap pembelian RTE food dari convenience store, in Seminar Nasional Teknik Industri (SNTI) IV. 107-1 - 107-6.

Wijanto, S. H. (2008) Structural Equation Modeling dengan LISREL 8.8: Konsep \& Tutorial (Edisi 1). Graha Ilmu. 